\title{
Inferior vena cava-syndrome
}

\author{
Peter Franz Klein-Weigel ${ }^{1}$, Saban Elitok ${ }^{2}$, Andreas Ruttloff ${ }^{1}$, Sabine Reinhold ${ }^{1}$, \\ Jessica Nielitz ${ }^{1}$, Julia Steindl ${ }^{1}$, Philippe Lutfi ${ }^{1}$, Lars Rehmenklau-Bremer ${ }^{4}$, \\ Birgit Hillner ${ }^{4}$, Heiko Fuchs ${ }^{3}$, Christian Wrase ${ }^{3}$, Thomas Herold ${ }^{4}$, and Lukas Beyer ${ }^{3}$ \\ ${ }^{1}$ Angiology - Interdisciplinary Center of Vascular Diseases, Ernst von Bergmann Klinikum Potsdam, Germany \\ ${ }^{2}$ Nephrology, Endokrinology/Diabetology, Ernst von Bergmann Klinikum Potsdam, Germany \\ ${ }^{3}$ Diagnostic and Interventionel Radiology, Ernst von Bergmann Klinikum Potsdam, Germany \\ ${ }^{4}$ Institute of Radiodiagnostic, Helios Klinikum Buch, Berlin, Germany
}

Summary: Inferior vena cava syndrome (IVCS) is caused by agenesis, compression, invasion, or thrombosis of the IVC, or may be associated with Budd-Chiari syndrome. Its incidence and prevalence are unknown. Benign IVCS is separated from malignant IVCS. Both cover a wide clinical spectrum reaching from asymptomatic to highly symptomatic cases correlated to the underlying cause, the acuity, the extent of the venous obstruction, and the recruitment and development of venous collateral circuits. Imaging is necessary to determine the underlying cause of IVCS and to guide clinical decisions. Interventional therapy has changed the therapeutic approach in symptomatic patients. This article provides an overview over IVCS and focuses on interventional therapeutic methods and results.

Keywords: Inferior vena cava syndrome, tumor compression, inferior vena cava thrombosis, Budd-Chiari syndrome, venous stenting, catheter-directed thrombolysis, thrombaspiration

\section{Introduction}

The inferior vena cava-syndrome (IVCS) is caused by agenesis, compression, invasion, stenosis, or thrombosis of the inferior vena cava (IVC). It may also be associated with Budd Chiari syndrome (BCS).

IVCS comprises a broad clinical spectrum [1-3]. The exact incidence and prevalence of IVCS are unknown [1, 2], but from the clinician's point of view it is seen less frequent than superior vena cava syndrome (SVCS) indicating that it is more often asymptomatic or oligosymptomatic [1].

In contrast to SVCS overviews addressing IVCS are scarce. The following article describes the clinical aspects and spectrum of the syndrome to enable the reader to suspect IVCS and to support diagnostic and therapeutic decisions. It will also focus on interventional techniques in the treatment of IVCS as these modalities have substantially changed the therapeutic approach in symptomatic patients.

\section{Etiology, anatomy, and pathophysiology}

The venous backflow from the lower half of the body, the pelvis, the genitals, and the lower extremities usually drains through the right and left iliac veins into the IVC. The IVC feeds about two third of the total venous return to the heart. Blood flow in the IVC is supported by the respiration cycle (increased flow during expiration) and by changes of the tricuspid valve level and atrial geometry associated with the cardiac cycle.

The IVC can be divided in different segments, which develop in a complex process early in gestation: (1) the suprahepatic IVC originates from the embryonic vitelline venous system (2) the suprarenal infrahepatic IVC from the embryonic subcardinal venous system (3) the infrarenal IVC from the embryonic supracardinal venous system (4) the iliac veins and the confluence region from the embryonic posterior cardinal vein [4]. Abnormal regression or persistence of these embryonic veins lead to congenital anomalies of the IVC [4, 5]. Most important, failure of the conjunction between the hepatic and prerenal segments results in infrahepatic interruption of the IVC with azygos continuation $[3,4,6]$. In this anomaly infrarenal IVC is intact, whereas the suprarenal portion of the IVC is absent. Blood is shunted through the retro-crural azygos vein, which becomes consecutively dilated [4-6]. The prevalence of the infrahepatic interruption of the IVC with azygos continuation is approximately $0.6 \%[4,5]$ and is sometimes accompanied by congenital heart defects, asplenia, or polysplenia syndromes $[4,5,7]$. In contrast, absence of the infrarenal IVC with preservation of the suprarenal segment of the IVC is very rare and it has been assumed that this condition is acquired by intrauterine or perinatal thrombosis of the IVC and not truly embryologic in origin [4].

Inferior vena cava anomalies have been recognized as risk factors for deep venous thrombosis (DVT) in children 
and young adults [8-10]. IVC anomalies occur in about $0.5 \%$ to $1 \%$ of the general population, and in $2 \%$ to $3 \%$ of patients with congenital heart defects $[4,9,10]$. Chee YL et al. and Ruggeri $\mathrm{M}$ et al. reported a prevalence of about $5 \%$ in younger DVT-patients $[9,10]$ and Bass JE et al. identified 5 (16\%) anomalous IVC in 31 younger patients with ilio-femoral DVT assessed by venography and magnetic resonance angiography [5]. Furthermore, analysis of the RIETE-registry revealed that patients with IVC-abnormalities are more likely to develop severe post-thrombotic syndrome after their first DVT than patients without IVC-anomalies [8].Thrombosis of the IVC was otherwise identified to be associated with primary thrombophilia, hormonal contraception, estrogen replacement therapy, Behcet's disease, paroxysmal nocturnal hemoglobinuria, and malignancies [11, 12]. IVC-filters increase the risk of IVC-thrombosis especially when anticoagulation therapy is withheld [11-13].

IVCS may also develop in Budd-Chiari syndrome (BCS), a rare occlusive disease affecting the hepatic veins (HV) and/ or the IVC [14-16]. French, Italian, and Swedish studies reported incidences of 0.69 to 2.2 per million inhabitants [17-19]. In Europe, BCS most often occurs in primary and secondary thrombophilia including hormone intake, Behcet's disease, paroxysmal nocturnal hemoglobinuria, and myeloproliferative syndromes [14, 16, 19, 20], whilst in Asia it is often caused by membranous or segmental stenoses or occlusions of the HV and/or the IVC [21]. Rarely, liver tumors or extrahepatic tumors compress or invade the IVC and/or the HV [14-16].

According to the location of the obstruction a truncal type (I) with occlusion of the hepatic segment of the IVC $\pm \mathrm{HV}$, a radicular type (II) with occlusion of the hepatic veins, and a veno-occlusive type (III) with obstruction of small centrilobular veins are differentiated [14, 15]. Types of IVCinvolvement in BCS have been characterized in more detail as the exact location and extend of these lesions influences interventional strategy. In type I and II-lesions there are segmental stenoses or occlusions of the IVC below the orifice of the HV, while in type III-lesions the stenoses or occlusions extend above the HV junction [14].

Symptoms and signs of BCS are unspecific and consist of abdominal pain, hepatomegaly, ascites, lower extremity swelling, and jaundice [14-16]. Diagnosis is made by duplex ultrasound, CE-CT with portal phase imaging, and /or properly timed CE-MRI $[14,16]$. BCS might lead to liver cirrhosis, portal hypertension, and hepatocellular carcinoma [14, 15]. The overall prognosis of the patients is reduced, but improved significantly during the last decades by the introduction of anticoagulation therapy and interventional procedures like recanalization of the stenosed or occluded VCI and hepatic veins, transjugular or direct intrahepatic porto-systemic shunt placement (TIPS, DIPS), or by orthotopic liver transplantation if all other modalities have failed $[14,15,18,19,21]$.

When the IVC becomes significantly obstructed venous pressure below the lesion rises including the pelvic and lower extremity veins. A pressure gradient $>3 \mathrm{~mm} \mathrm{Hg}$ correlating with a Doppler peak velocity ratio of $>2.5$ across the lesion was defined to characterize a $>50 \%$ stenosis [22]. Nevertheless, in patients selected for interventional therapy pressure gradients in the IVC often reach doubledigit values [see literature in the interventional therapy sections].

Venous congestion in the lower body usually leads to anasarca, ascites, genital edema, and lower extremity swelling $[1,3,11]$. On the other hand, anatomically preformed collaterals enlarge under increased pressure conditions supporting venous backflow [2]. Thus, the development and the severity of symptoms in IVCS is correlated with the acuity and extent of the venous obstruction and is inversely correlated with the recruitment or development of venous collateral circuits $[2,11]$.

In humans, there are preferred collaterals from the IVC to the superior vena cava (SVC) and the right heart, which can be divided into four major pathways [2]: (1) the deep pathway comprising the intravertebral, paraspinal, extravertebral venous plexus, and the ascending lumbar veins, which anastomose with the azygos-hemiazygos-venous system (2) the intermediate pathway including the periureteric venous plexus, the gonadal veins and the renal veins, which drain into the IVC (3) the superficial pathway via the inferior and superior epigastric veins and the mammary veins to the subclavian veins and/or through the circumflex iliac veins, the lateral thoracic veins, and the axillary veins [2]. The most important of these collateral circuits is the deep pathway, which is connected to the azygos-hemiazygos system.

Cardiac output in IVCS is usually preserved. Nevertheless, cardiac preload and cardiac output reserve was shown to be reduced in severe IVC stenosis under exercise conditions [23]. Only in acute complete IVC thrombosis or thrombosis of collaterals, in cases of preexisting chronic heart failure, and in mass compression of the central veins or the heart itself cardiac output might already be compromised under resting conditions [11, 24-26].

Renal vein outflow obstruction might develop by renal vein thrombosis or obstruction, leading to renal proteinuria, hematuria, impaired renal function, or even pelvic congestion syndrome $[1,2]$.

Malignant IVCS was described in patients with renal carcinomas, adrenal carcinomas, pheochromocytomas, pancreatic carcinomas, hepatocellular carcinomas, ovarian carcinomas, cervical carcinomas, prostatic cancer, gastric cancer, retroperitoneal sarcomas, metastatic malignant disease involving the pelvic and retroperitoneal lymph nodes, and primary lymphomas [11, 12, 27-32]. Rarely, primary tumors of the IVC like endotheliomas and leiomyosarcomas were found $[33,34]$.

Benign causes of IVCS are enlarged caudate lobes in patients with liver cirrhosis, giant liver and renal cysts, granulomatous diseases, Crohn's disease, aortic aneurysms, retroperitoneal hematomas, retroperitoneal fibrosis, and even blunt abdominal trauma [35-39]. 


\section{Clinical symptoms}

Symptoms in IVCS vary greatly [1]. Patients may be asymptomatic or oligosymptomatic despite significant IVCobstruction or otherwise present with edemas of the lower body, the genitals, and the lower extremities. Ascites or jaundice may also be present. Patients with acute or subacute IVC-thrombosis or tumors often complain of abdominal pain, back pain, and/or pelvic pain radiating to the groin $[1,11]$. In more chronic courses dilated and tortuous superficial veins on the abdomen, the thoracic wall, and the lower extremities indicate collateral formation and signs of chronic venous disease with leg swelling, discolorations, ulcers, and venous claudication may be present $[1,3]$. Renal vein involvement is indicated by flank pain, proteinuria, and hematuria resembling nutcracker syndrome, which might otherwise develop independently of IVC-obstruction or compression. Pelvic congestion syndrome might be seen in patients where the intermediate collateral pathway is generated [2].

\section{Establishing diagnosis}

The diagnosis of IVCS is based on clinical grounds [1,3]. As the etiology covers a broad spectrum of pathologies imaging is necessary to determine the underlying cause and guide therapeutic decisions. Diagnostic instruments are duplex ultrasound, contrast enhanced ultrasound (CEUS), intravascular ultrasound (IVUS), contrast-enhanced MRI and CT, and FDG PET-CT.

Diagnosis of IVC pathologies is challenging with duplex ultrasound (DUS) for some reasons: (1) IVCS is rare and may be ignored, when exclusion of a lower extremity thrombosis is in the focus of the examiner (2) direct visualization of the iliac veins and the IVC is often hampered by bowl gas or massive abdominal adiposity (3) diagnosis highly depends on the experience of the examiner.

Regardless of its limitations, DUS is the modality of choice for an initial screening examination [11, 12, 14-16, $40,41]$. As has been shown by Lin et al. monophasic waveforms in the common femoral veins or the external iliac veins are reliable indicators of proximal venous obstruction [40], as in case of endoluminal obstruction or external compression respiratory variation of the Doppler waveform is dampened, resulting in a monophasic constant flow curve (see Figure 1). If this flow pattern is present in both femoral veins involvement of both iliac veins and/or the IVC is signified [41]. Furthermore, reversed flow in the superficial epigastric veins indicate for iliaco-caval occlusion or compression [42]. Thus, a monophasic flow-pattern in both femoral veins and/or a reversed flow in the superficial epigastric veins inevidently indicates a closer examination of the proximal venous tracts [40-42].

If good ultrasonographic views can be obtained the exact diagnosis (IVC-thrombosis, stenosis, tumor compression, IVC-anomaly) may be established by DUS alone [41]. Contrast-enhanced ultrasound (CEUS) is useful for the detection of IVC-thrombosis and in differentiating bland thrombus from tumor invasion [43]. Intravascular ultrasound (IVUS) reliably detects pathologies affecting the IVC wall and the luminal space [44, 45]. Moreover, IVUS is the method of choice for quantifying venous stenoses and guiding venous interventions [44].

Pressure measurements are also helpful to determine the hemodynamic significance of a stenotic IVC-lesion. According to Labropoulos threshold pressure gradient $>3.0 \mathrm{~mm} \mathrm{Hg}$ indicates a $\geq 50 \%$ stenosis [22]. Thus, if there is a pressure gradient clearly above this level a significant stenotic IVC segment is signified.

Appropriately timed CE-CT and CE-MRI (resp. MR-venography) are essential for better overview and the planning of an venous intervention [11, 12, 46-51]. Nevertheless, there are some potential pitfalls, which are critical to avoid misdiagnosis (f.e. flow-related pseudo-filling defects on the level of the renal veins, ferro-magnetic artefacts due to IVC filters and stents) [11, 46-48, 50, 52], while findings such as a flat IVC and early enhancement of the IVC limit differential diagnoses [46]. CE-CT is also recommended for the identification of complications related to IVC filters [52].

Differentiating tumor invasion in the IVC from bland thrombus formation is of special clinical interest. Comparing DUS, MRI, and CT highest sensitivity was found for MRI (77.8\%), highest specificity for CE-MRI and CECT (97.4\%) [53]. Other authors advocate CEUS, IVUS, or FDG PET-CT [43, 53, 54], which is otherwise extremely sensitive for the detection of retroperitoneal and intraabdominal malignancies and metastases.

Sonography is the diagnostic screening method of choice in BCS [14, 16, 55]. Common findings in B-mode sonography include IVC thrombi and webs, IVC stenosis, hepatic venous thrombosis or stenosis, enlarged caudate lobe, intrahepatic lesions, ascites, and intrahepatic or extrahepatic collaterals, while in DUS monophasic to absent flow in the hepatic veins and in the IVC, and/or high flow velocities in stenotic lesions can be detected $[14,16,55,56]$. The combination of specific signs including thrombosis, stenosis, fibrotic cords, or insufficient recanalization of the hepatic veins or the IVC in combination with an enlarged caudate lobe offered the highest predictive value to identify patients with BCS (specificity 100\%) [55]. In a study performed by Faraoun et al. a total of 176 patients with primary BCS were diagnosed by DUS, CE-CT and CE-MRI. Hepatic vein obstruction was a constant finding associated with IVC-abnormalities in $29 \%$ patients, obstruction of the three hepatic veins was present in $89.8 \%$ of the cases, and longstanding thrombus in the hepatic veins was observed in more than $92 \%$ of patients with all three imaging methods. Agreement between DUS, CT, and MRI was perfect in the identification of hepatic vein thrombus $(\kappa=0.9)$, but was only slight to moderate in revealing the type of hepatic vein abnormality [57] Thus, DUS in combination with MRI or CT seems to represent the best imaging strategy in BCS $[14,16,55,57]$.

Venography is nowadays restricted to patients selected for interventions. If performed, at least two projections 


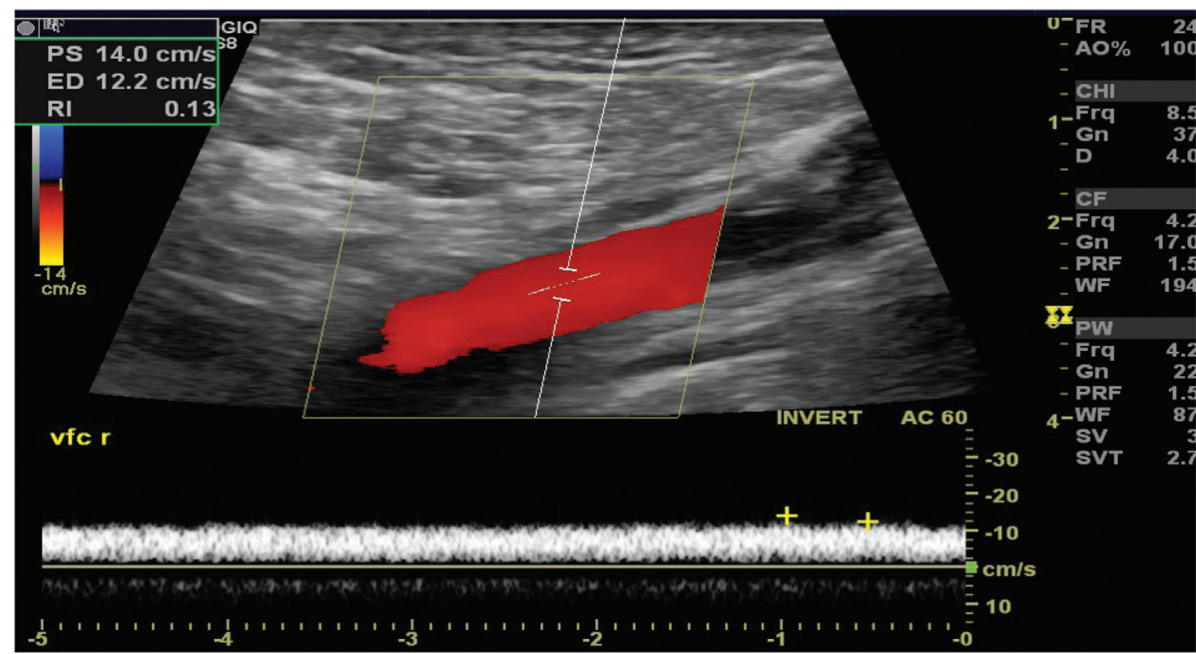

Figure 1. Monophasisc constant flow curve in the right common femoral vein due to an extended retroperitoneal mass compressing the right iliac vein and the IVC.

(posterior-anterior and lateral) are necessary. Things might appear normal in one projection but turn out to be pathologic from another perspective [58].

\section{Establishing tumor diagnosis}

IVCS is associated with a wide spectrum of malignancies. Imaging data usually enables radiologists and oncologists to narrow the differential diagnoses and to define staging strategies [59-66]. Nevertheless, histology and molecular genetics are important for an exact tumor diagnosis and often determine therapeutic decisions and over-all prognosis. Sonography- or CT-guided biopsy, endoscopy, endosonography, and video-assisted laparoscopy may be indicated depending on the suspected tumor entity, location, and local spread, while additional bone marrow aspiration is indicated in patients with suspected lymphomas.

\section{Therapeutic strategies}

Therapeutic decisions in IVCS are determined by the patient's clinical condition, the underlying etiology, the balance between risk and benefit and the availability of therapeutic procedures in the institution.

Patients with IVCS usually present in a stable clinical condition which allows elective diagnostic imaging and interdisciplinary treatment decisions.

In case of VCI-thrombosis anticoagulation should be initiated and an interdisciplinary team of vascular physicians should decide about additional invasive procedures like thrombaspiration and/or thrombolytic therapy [11, 12, 67]

Obtaining a histologic diagnosis is essential for oncologic decision making but implicates some time delay. Stent therapy in tumor patients provides rapid symptomatic relieve within hours to days and does not interfere with biopsy [1]. Thus, in a symptomatic patient with unknown histologic diagnosis stenting is a prior-ranking option, while patients with known radio- or chemotherapy-sensitive tumors like lymphomas may be primarily treated with these modalities [1].

In BCS therapeutic intervention is based on the acuity and extend of symptoms in an established stepwise approach $[14,15,21]$.

\section{Interventional therapy in patients with malignancy}

Stenting in malignant IVCS is indicated: (1) in patients with severe symptoms (2) in case of persistency of symptoms despite radio- and/or chemotherapy, and (3) in patients in whom chemotherapy and radiation are contraindicated or of minor effectiveness [modified according to 1].

The literature regarding stent placement in malignant IVCS is limited [1]. Table I summarizes technical and clinical results of interventions in patients with malignancies published between 1998 and 2020 [68-72]. Obviously, the Wallstent and the Cianturco-Z-Stent are most frequently used. Increased post-stent placement pressure gradients indicating residual stenosis correlated with worse outcomes [70]. The Stanford group also correlated technical problems and complications to the use of Wallstents and described decreased stent adherence to the IVC-wall as a result of inadequate mechanical properties indicating that inadequate stent design, insufficient stent diameters, and inadequate radial force of the stents might be critical issues [70]. Indeed, almost all stents used in the published series were not primarily designed and/or approved for venous stenting, which might have negatively influenced the results [73]. On the other hand, in the only series published with a relevant quota of venous dedicated stents (53\%) technical success rates and patency rates did not exceed those performed with arterial stents [69].

In the hands of experienced interventionalists working in specialized centers stenting of malignant IVCS is associated with acceptable complication rates (see Table I). Nevertheless, stenting in the IVC implies a high degree of technical 


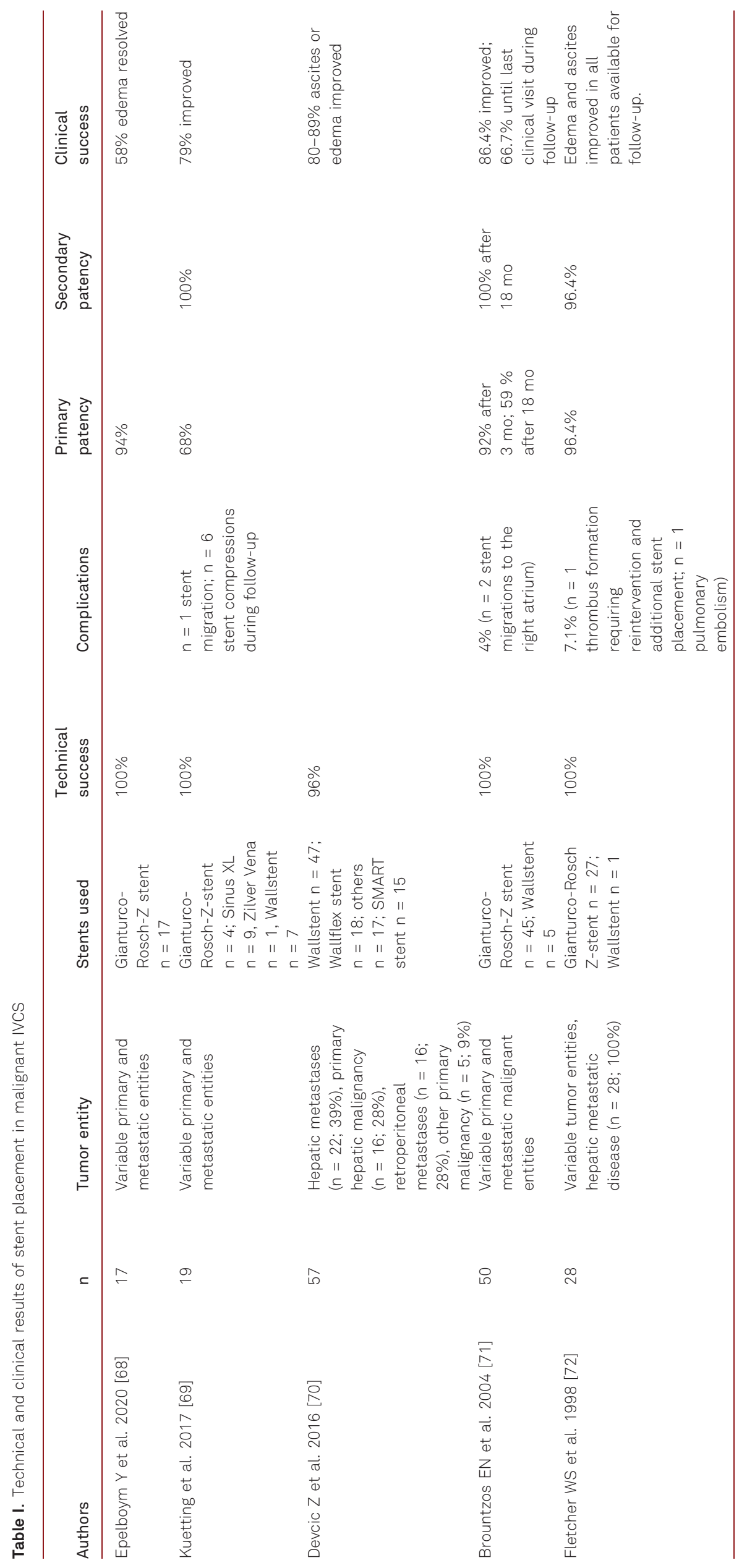



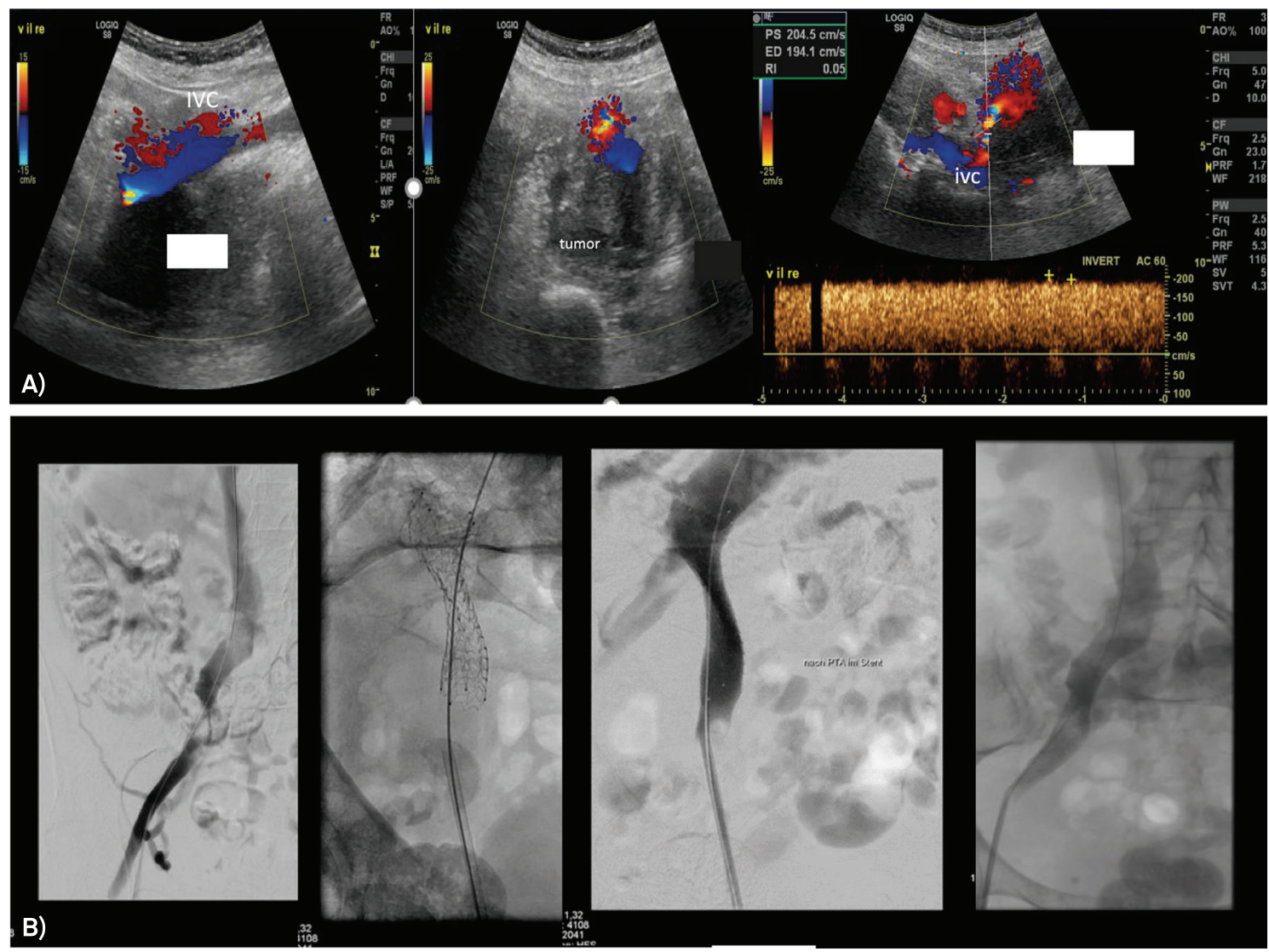

Figure 2. A) Color-coded ultrasound showing compression of the iliaco-caval junction by a retroperitoneal tumor mass. B) (same patient as in figure 2 a) partial tumor compression of the IVC and high-grade tumor compression of the iliac vein. Partial compression of the venous dedicated stent due to the tumor mass and final result.

complexity. IVC tears and rupture, stent thrombosis, stent migration into the heart, pulmonary embolism, retroperitoneal and groin hematomas, and hemopericardium are potential threats [68-72].

Stent placement in malignant IVCS often is a palliative procedure. Median survival rates in the reported series are low. In the series of Fletcher et al. including patients with hepatic metastatic disease the median survival was only 27.5 days, while in the series of Brountzos et al. and Devcic a mean survival of 75 resp. 104 days was reported [70-72].

There are no randomized trials addressing antiplatelet or antithrombotic therapy after successful interventional therapy in malignant IVCS. Nevertheless, most centers prefer at least a short-term antiplatelet and/or anticoagulation treatment regime [68-72]. Figures 2A-2B show an extented retroperitoneal mass (retroperitoneal sarcoma) compressing the IVC and the right iliac vein treated by venous stenting and PTA.

\section{Interventional therapy in IVCS of benign origin}

Benign IVCS most often results from chronic obstructions or stenoses of the IVC due to congenital IVC abnormalities and/or previous IVC thrombosis [4, 8, 9, 11, 12, 67, 74].
In contrast to chronic iliac vein obstruction only smaller series or individual cases have been published. Table II summarizes technical and clinical results published more recently in collectives with benign IVCS unrelated to IVCfilters [75-80].

As was reported by Neglén et al. and Delis et al. successful IVC stenting not only translated into clinical improvement, but also into improvement of venous hemodynamic parameters like venous outflow fraction, calf muscle pump function, venous pressure, and venous reflux [81, 82].

In the hands of experienced interventionalists overall complication rates are low (see Table II). Nevertheless, life threatening complications like bleeding associated with IVC tears, stent migration into the heart, pulmonary embolism, and hemopericardium may occur $[44,75-80]$

Patients with thrombotic IVCS successfully treated with stents are at increased risk of subsequent stent thrombosis. Stent thrombosis correlated with younger age $(<40 \mathrm{y})$, extensive stenting especially below the common femoral vein, and structurally altered inflow veins in the Swiss registry $[83,84]$.

Filter-related IVC-occlusions pose special technical problems for the interventionalist as the obstructed filter must either be removed, balloon-dilated, or stented [11, 13, 8590]. Filter removal bears significant risks, especially in case of wall perforation, stent extravasation, or stent fracture requiring advanced removal techniques with increased 


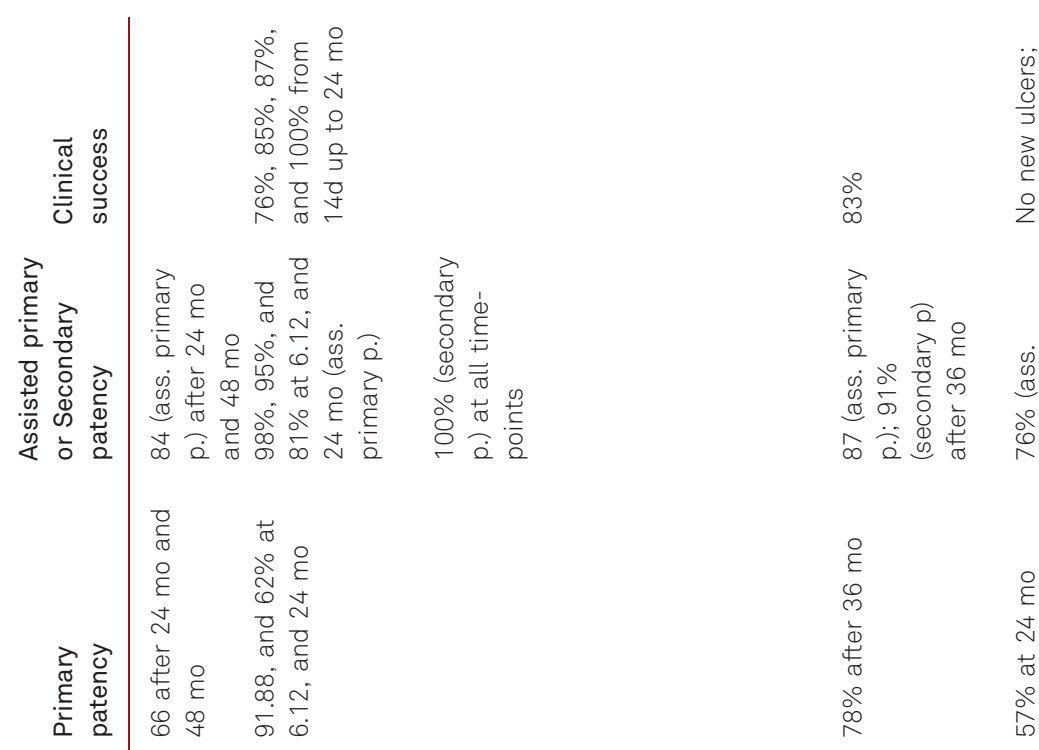

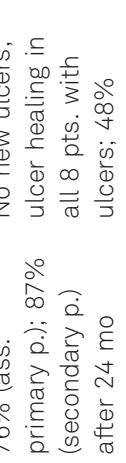

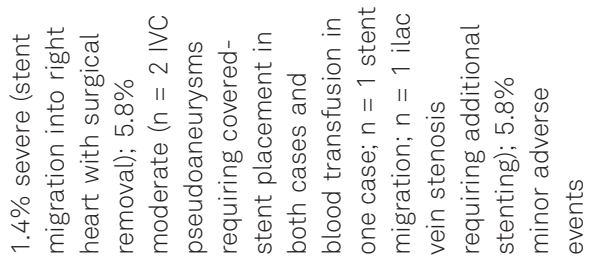

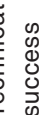

○े

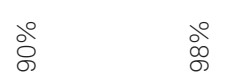

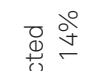

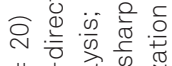

II

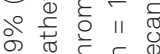

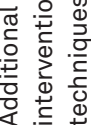

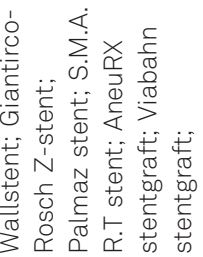

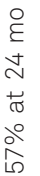

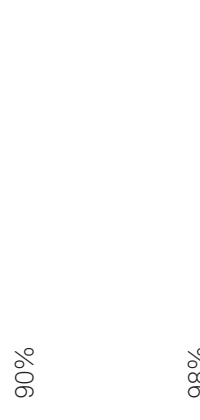

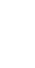

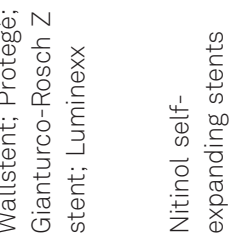

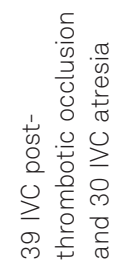

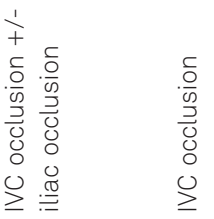

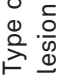

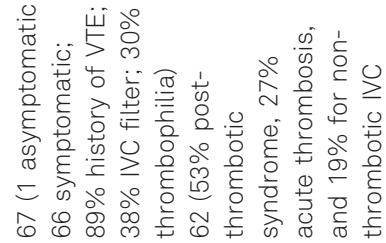

$=$ के \&

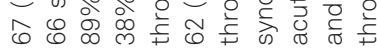




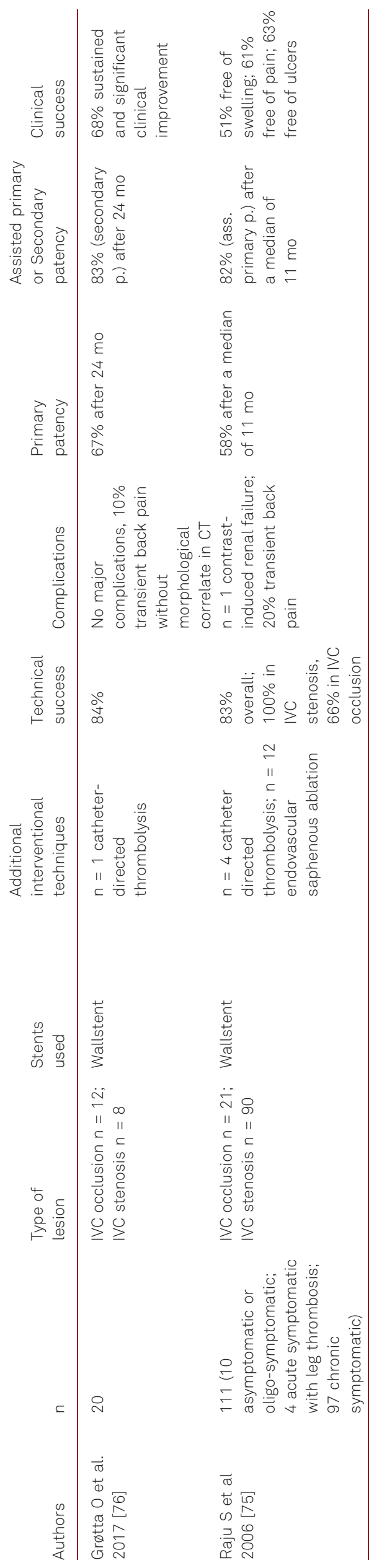

major complication rates in up to $5 \%$ of the cases even in the hands of experienced venous interventionalists [86, 87]. Risk might be minimized by a second access with a stiff guidewire placed in the superior vena cava. If extravasation occurs a 18 or $20 \mathrm{~mm}$ balloon can then be placed quickly over the Amplatzer wire and inflated for sealing. As an alternative to filter removal recanalization and stenting of a chronically obstructed filter has been advocated [88-90]. In the largest series published by Chick et al 2017 comprising data from 120 patients with 123 IVC filters as well as in smaller series technical success was high and primary and secondary patency did not significantly differ from those reported in non-filter-related IVC lesions [88-90].

For the prevention of filter related complications IVC filters should be retrieved once the patient can be adequately anticoagulated. Figures $3 \mathrm{~A}-3 \mathrm{C}$ illustrate a rare case of a restenosis after implantation of a IVC-prothesis treated by venous stenting and PTA.

Unfortunately, evidence-based recommendations addressing the kind and the duration of antiplatelet and/ or anticoagulation therapy after interventional procedures in benign IVCS do not exist. In IVCS related to a previous thrombosis long-term anticoagulation may be preferred.

\section{Interventional therapy in acute IVC thrombosis}

Although anticoagulation therapy remains fundamental in the treatment of acute IVC thrombosis additional endovascular options including transcatheter thrombolysis, vacuum assisted or mechanical thrombectomy, or a combination of these techniques are increasingly used as acute IVC thrombosis is associated with an excess mortality and morbidity under conservative treatment [11, 12, 67].

Catheter directed thrombolysis and interventional thrombectomy techniques have widely replaced open surgical thrombectomy $[11,67]$. In the U.S.A. catheter-directed thrombolysis (CDT) steadily increased according to the Nationwide Inpatient Sample database [91]. However, based on this registry and a propensity-matched control group, no differences in the hospital stay and over-all mortality were found between the CDT and the anticoagulation groups, but higher rates of pulmonary embolism $(12.1 \%$ versus $7.8 \%)$, intracranial hemorrhage $(1.6 \%$ versus $0.2 \%)$, and acute renal failure (13.9\% versus $9.4 \%$ ) were reported in the CDT group [91]. Unfortunately, randomized head-to-head comparisons are not available.

Only anecdotical evidence exists for beneficial effects of ultrasound-enhanced thrombolysis in acute IVC-thrombosis or iliaco-caval thrombosis $[92,93]$. Given the large diameter of a thrombosed IVC it is questionable whether the technical principle of ultrasound-enhanced thrombolysis provides an advantage over conventional CDT. Moreover, a recently published Dutch trial failed to demonstrate significantly lower rates of post-thrombotic syndrome in patients with iliaco-femoral thrombosis occasionally ascending into the 

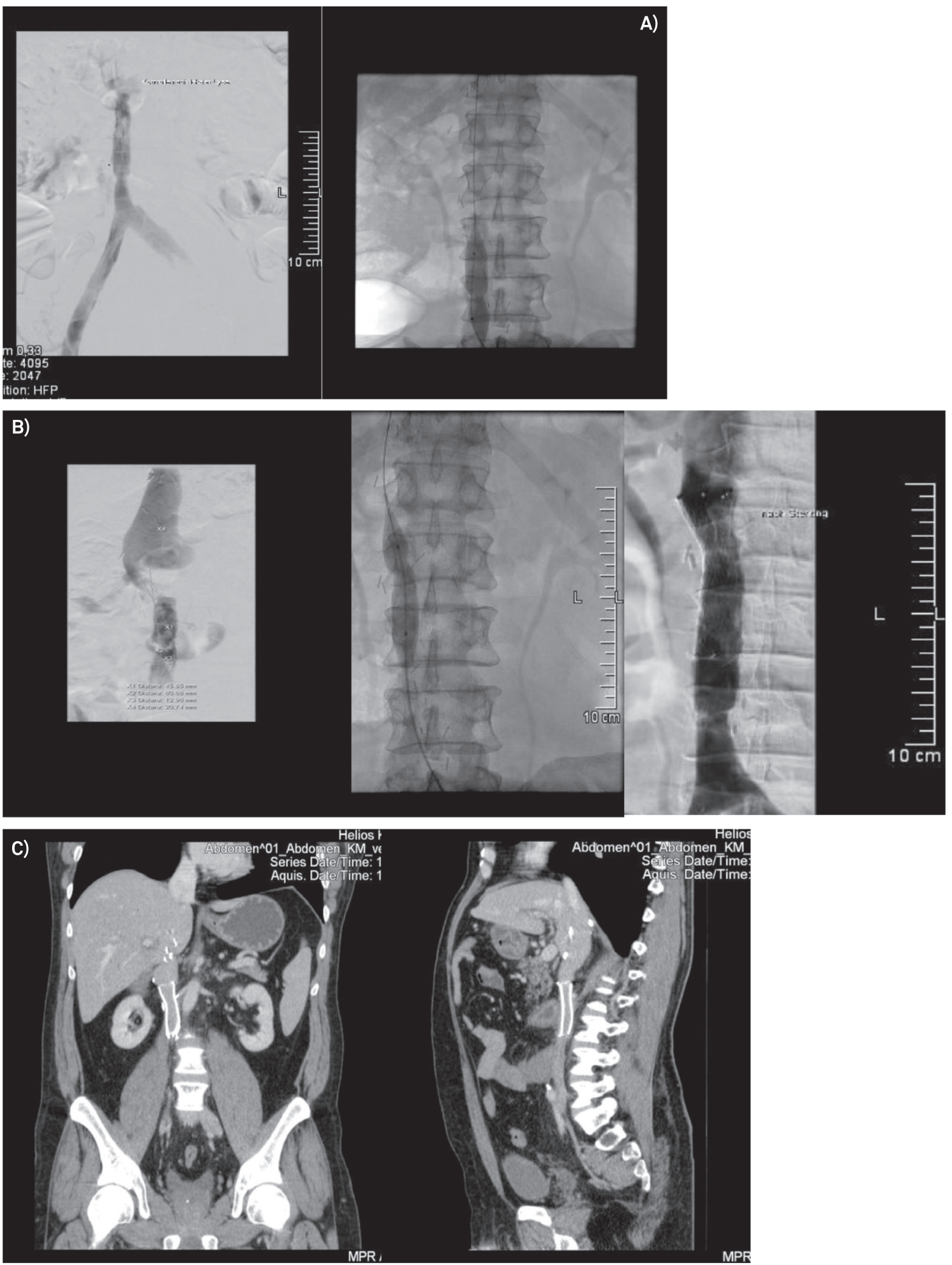

Figure 3. A) Medium grade stenosis at the distal end of the IVC-prothesis treated by balloon dilation. B) Same patient as figure 3a. High-Grade Stenosis at the proximal end of the IVC-prothesis with marked post-stenotic dilation. Predilation and final result after implantation of a dedicated venous stent. C) CT-A one year after IVC-Stenting.

IVC treated with ultrasound-enhanced thrombolysis [94]. A lack of evidence also exists for percutaneous mechanical, rheolytic, and vacuum thrombectomy [95-98]. Compared to CDT these techniques are timesaving and may help to avoid bleeding complications. They proved useful and safe in acute iliaco-femoral thromboses occasionally ascending into the IVC [95-101].
Although anticoagulation is the mainstay for patients with acute IVC thrombosis [11, 12, 67], there is no evidence-based recommendation how long anticoagulation therapy should be maintained after a successful interventional therapy [11]. Again, in IVCS related to thrombosis long-term anticoagulation may be preferred at least in cases without identifiable trigger-mechanisms. 


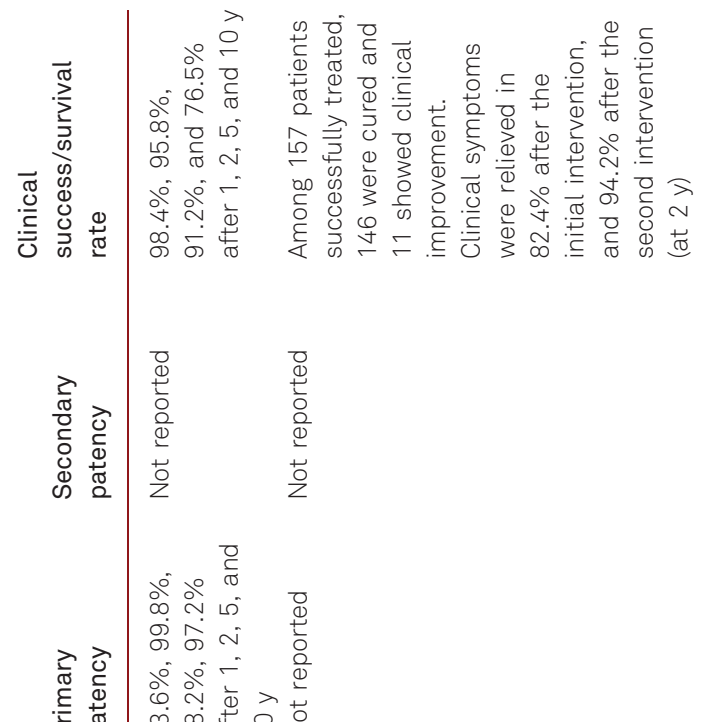
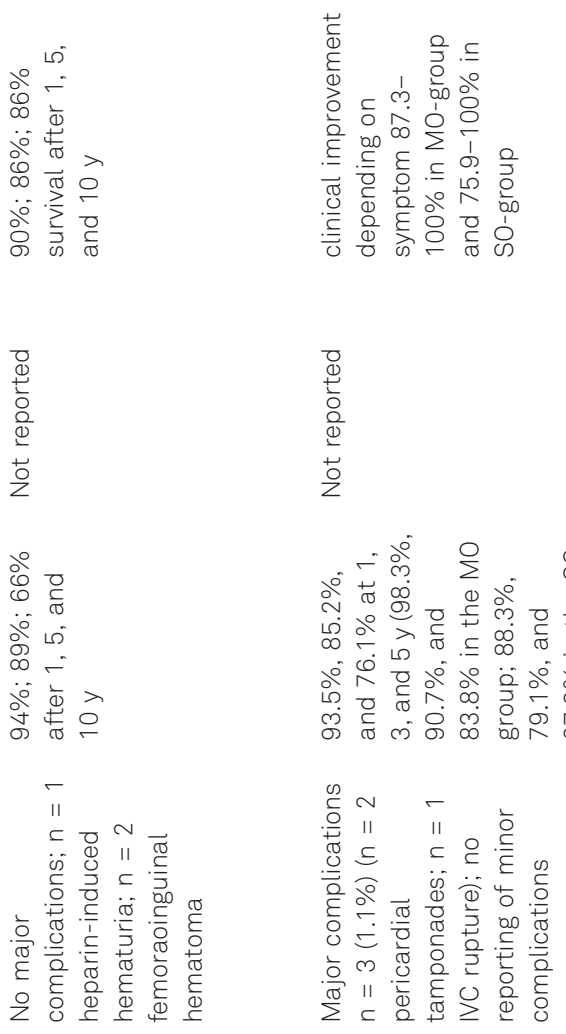

iे

官

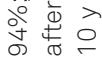

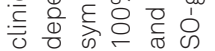

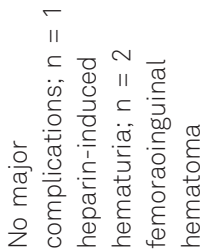

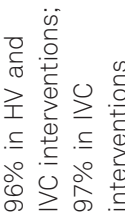

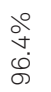

$\stackrel{\stackrel{\circ}{\circ}}{\stackrel{\circ}{\circ}}$

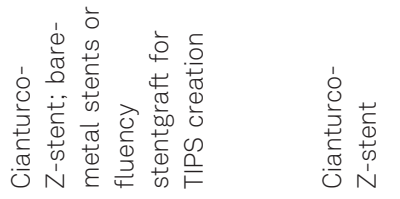

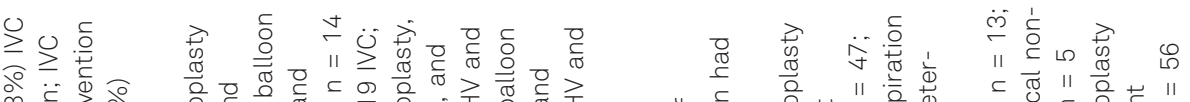

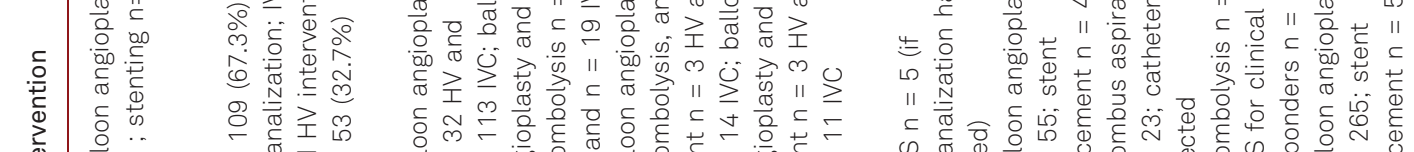




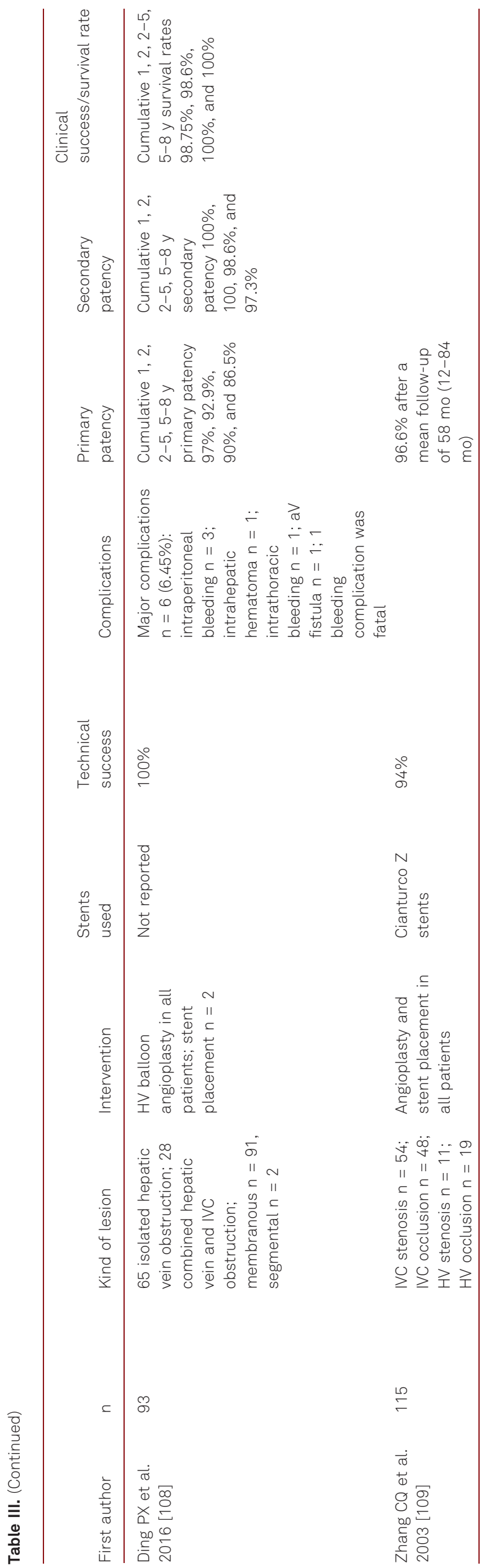

\section{Interventional therapy in Budd-Chiari syndrome}

Recanalization procedures in BCS are restricted to cases with obstruction and/or thrombosis of the IVC and the larger hepatic veins, while in diffuse HV-obstruction and in veno-occlusive type interventional recanalization is impossible $[14,15]$. These cases are either treated conservatively, with TIPS/DIPS creation, or with liver transplantation in case of progressive liver failure [14, 15].

While BCS in western countries is almost exclusively caused by thrombosis BCS in Asia is usually a consequence of membranous or segmental lesions in the IVC and/or the HV [21, 102-104]. Thus, interventional approaches differ between the orient and occident with much more recanalization procedures being performed in Asia [14, 21, 102104].

Table III summarizes technical and clinical results of balloon dilation and stenting (often in combination with sharp recanalization) in larger series from Asia [103, 104]. As can be seen, technical and clinical success rates of balloon angioplasty and/or stenting are high and have considerably contributed to an improved prognosis of the patients [21, 103-109].

Minor and major complication rates of the highly experienced centers are low (see Table III) [21, 102-110]. The rate of HV or IVC-rupture was reported to be $<1 \%$ in a monocenter report focusing on bleeding complications associated with balloon angioplasty in BCS patients [111]. Higher complication rates were reported in transhepatic angioplasty of the HV and in sharp (needle) recanalization procedures [112-114].

Comparing recanalization techniques in of $\mathrm{HV}$ and IVC with direct intrahepatic portosystemic shunt creation, Mukund et al. found improved liver synthesis functions in recanalization compared to patients treated with DIPS. Nevertheless, mortality did not differ between the groups [115].

BCS-Patients with thrombotic lesions are either managed conservatively with long-term anticoagulation or receive pre-interventional treatment with anticoagulant drugs to reduce clot burden [116, 117]. Alternatively, primary interventional strategies with thrombus aspiration, thrombus retrieval, and/or catheter-directed thrombolysis followed by stent placement have been advocated [118121]. Technical success, mid-term, and long-term result of these intervention do not seem to differ substantially from recanalization procedures in non-thrombotic lesions [118121].

Long-term anticoagulation after interventional therapy of BCS is recommended to avoid re-thrombosis and stent occlusion [21].

\section{Conclusions}

IVCS is a complex condition best managed by an interdisciplinary team approach. In the last decades percutaneous 
interventional techniques have fundamentally changed therapeutic strategies in symptomatic patients in benign and malignant IVCS as well as in IVCS associated with BCS. Interventions in IVCS and BCS are complex procedures, which should best be concentrated in specialized centers. Despite increasing knowledge many clinically important questions in the management of IVCS patients remain unsolved including optimized patients' selection strategies for interventions, differential procedural considerations, optimized devices, and antithrombotic and antiplatelet treatment regimens to avoid restenosis and -thrombosis.

\section{References}

1. Friedman T, Quencer KB, Kishore SA, Winokur RS, Madoff DC. Malignant venous obstruction: superior vena cava syndrome and beyond. Semin Intervent Radiol. 2017;34: 398-408.

2. Sonin AH, Mazer MJ, Powers TA. Obstruction of the inferior vena cava: a multiple-modality demonstration of causes, manifestations, and collateral pathways. Radiographics. 1992;12:309-22.

3. Missal ME, Robinson JA, Tatum W. Inferior vena cava obstruction: clinical manifestations, diagnostic methods, and related problems. Ann Intern Med. 1965;62:133-61.

4. Ghandour A, Partovi S, Karuppasamy K, Rajiah P. Congenital anomalies of the IVC - embryological perspectives and clinical relevance. Cardiovasc Diagn Ther. 2016;6:482-92.

5. Bass JE, Redwine MD, Kramer LA, Huynh PT, Harris JH Jr. Spectrum of congenital anomalies of the inferior vena cava: cross-sectional imaging findings. Radiographics. 2000; 20:639-52

6. Piciucchi S, Barone D, Sanna S, Dubini A, Goodman LR, Oboldi D, et al. The azygos vein pathway: an overview from anatomical variations to pathological changes. Insights Imaging. 2014;5:619-28.

7. Cheung CKM, Law MF, Wong KT, Tam MTK, Chow KM. Massive pulmonary embolism in a patient with polysplenia syndrome and interrupted inferior vena cava with azygous continuation. Arch Med Sci. 2018;14:251-3.

8. Tufano A, López-Jiménez L, Bikdeli B, García-Bragado F, Mazzolai L, Amitrano M, et al.. RIETE Investigators. Inferior vena cava agenesis in patients with lower limb deep vein thrombosis in the RIETE registry. When and why to suspect. Int J Cardiol. 2020;305:115-9.

9. Chee YL, Culligan DJ, Watson HG. Inferior vena cava malformation as a risk factor for deep venous thrombosis in the young. Br J Haematol. 2001;114:878-80.

10. Ruggeri M, Tosetto A, Castaman G, Rodeghiero F. Congenital absence of the inferior vena cava: a rare risk factor for idiopathic deep-vein thrombosis. Lancet. 2001;357:441.

11. Alkhouli M, Morad M, Narins CR, Raza F, Bashir R. Inferior vena cava thrombosis. JACC Cardiovasc Interv. 2016;9:62943.

12. Shi W, Dowell JD. Etiology and treatment of acute inferior vena cava thrombosis. Thromb Res. 2017;149:9-16.

13. Alkouhli M, Bashir R. Inferior vena cava filters in the United States: less is more. Int J Cardiol. 2014;177:742-3.

14. Grus T, Lambert L, Grusová G, Banerjee R, Burgetová A. Budd-Chiari Syndrome. Prague Med Rep. 2017;118:69-80.

15. Valla DC. Budd-Chiari syndrome/hepatic venous outflow tract obstruction. Hepatol Int. 2018;12(Suppl 1):168-80.

16. Van Wettere M, Bruno O, Rautou PE, Vilgrain V, Ronot M. Diagnosis of Budd-Chiari syndrome. Abdom Radiol. 2018;43:1896-907.
17. Ollivier-Hourmand I, Allaire M, Goutte N, Morello R, Chagneau-Derrode C, Goria O, et al. French Network for Vascular Disorders of the Liver. The epidemiology of BuddChiari syndrome in France. Dig Liver Dis. 2018;50:931-7.

18. Ageno W, Dentali F, Pomero F, Fenoglio L, Squizzato A, Pagani $G$, et al. Incidence rates and case fatality rates of portal vein thrombosis and Budd-Chiari Syndrome. Thromb Haemost. 2017;117:794-800.

19. Rajani R, Melin T, Björnsson E, Broomé U, Sangfelt P, Danielsson A, et al. Budd-Chiari syndrome in Sweden: epidemiology, clinical characteristics and survival - an 18year experience. Liver Int. 2009;29:253-9.

20. Shindo S, Motohashi S, Kaga S, Inoue H, Matsumoto M, Shindo H. Paroxysmal nocturnal hemoglobinuria: complete resolution of an occluding inferior vena caval thrombus. Abdom Imaging. 2007;32:754-7.

21. Cheng DL, Zhu N, Xu H, Li CL, Lv WF, Fang WW, et al. Outcomes of endovascular interventional therapy for primary Budd-Chiari syndrome caused by hepatic venous obstruction. Exp Ther Med. 2018;16:4141-9.

22. Labropoulos N, Borge M, Pierce K, Pappas PJ. Criteria for defining significant central vein stenosis with duplex ultrasound. J Vasc Surg. 2007;46:101-7.

23. Eleid MF, Bjarnason H, Frye RL, Nishimura RA. Exercise right heart catheterization for inferior vena cava obstruction: confirming the hemodynamic significance of an anatomic lesion. Catheter Cardiovasc Interv. 2014;83:E105-8.

24. White JA, Fine NM, Shargall Y. Images in cardiovascular medicine. Pectus excavatum with compression of the inferior vena cava: a rare cause of recurrent syncope. Circulation. 2009;120:1722-4.

25. Knodel DH, Kirk JW. Ovarian cancer manifested as exertional hypotension due to obstruction of the inferior vena cava. South Med J. 1988;81:1193-5.

26. Nicolau PB, Lázaro JL, Viladomiu L, Casabiel XM, RiveiroBarciela M. Inferior cava vein syndrome and heart compression due to a giant liver cyst. Am J Gastroenterol. 2017;112:984.

27. Alghulayqah A, Alghasab N, Amin T, Alkahtani N, Farhat R, Alzahrani AS. Long-term recurrence-free survival of adrenocortical cancer extending into the inferior vena cava and right atrium: Case report and literature review. Medicine (Baltimore). 2017;96:e6751

28. Bangash HK, Hayne D, Thyer IA. Metastatic primary testicular carcinoid tumor managed with radical orchiectomy, retroperitoneal lymph node dissection and inferior vena cava excision: Case report. Urol Case Rep. 2017;15:56-8.

29. Murata M, Inui K, Ikeda Y, Hasegawa G, Nakagawa Y, Nishiyama T, Tomita Y. Retroperitoneal extragonadal seminoma developed with acute lower inferior vena cava syndrome: A case report. Urol Case Rep. 2018;20:72-4.

30. Patel SA. The inferior vena cava (IVC) syndrome as the initial manifestation of newly diagnosed gastric adenocarcinoma: a case report. J Med Case Rep. 2015:9:204.

31. Gagné-Loranger M, Lacombe L, Pouliot F, Fradet V, Dagenais F. Renal cell carcinoma with thrombus extending to the hepatic veins or right atrium: operative strategies based on 41 consecutive patients. Eur J Cardiothorac Surg. 2016;50:317-21

32. Ferraris M, Callegaro D, Barretta F, Fiore M, Radaelli S, Stacchiotti S, Miceli R, Socrate AM, Locati P, Gronchi A. Outcome of iliocaval resection and reconstruction for retroperitoneal sarcoma. J Vasc Surg. Venous Lymphat Disord. 2019;7:547-56.

33. Balraj P, Kabbani L, Mathews J, Tinney F Jr, Schwartz S, Kwon D, et al. Epithelioid hemangioendothelioma presenting as inferior vena cava obstruction diagnosed using an endovascular thrombectomy device. Ann Vasc Surg. 2017;40:294e.

34. Alkhalili E, Greenbaum A, Langsfeld M, Marek J, Rana MA, Glew R, et al. Leiomyosarcoma of the Inferior vena cava: a 
case series and review of the literature. Ann Vasc Surg. 2016;33:245-51.

35. Murakami N, Arai Y, Takagawa Y, Okuma K, Takahashi K, Inaba $K$, et al. Inferior vena cava syndrome caused by retroperitoneal fibrosis after pelvic irradiation: A case report. Gynecol Oncol Rep. 2018;27:19-21.

36. Shukuzawa K, Toya N, Momokawa Y, Fukushima S, Akiba T, Ohki T. Pulmonary embolism due to inferior vena cava compression by a retroperitoneal hematoma after endovascular repair of a ruptured abdominal aortic aneurysm. Case Rep Vasc Med. 2017;2017:8172549.

37. Sashi R, Ito I, Watarai J, Miura K, Horie Y. Thrombophlebitis of the inferior vena cava involving the retroperitoneum with Crohn's disease: MR demonstration. Magn Reson Imaging. 1997;15:1099-101.

38. Moore RD, Rutter ED, Zapko DR, Kolade VO, Ayyoub SM. Abdominal aortic aneurysm with inferior vena cava compression in association with deep venous thrombosis. Am J Med Sci. 2013;346:521-2.

39. Parmar K, Thakur A, Sharma A, Kumar S. Isolated renal vein and inferior vena cava thrombus following blunt trauma abdomen. A rare case scenario. Trauma Case Rep. 2020; 9(25):100282.

40. Lin EP, Bhatt S, Rubens D, Dogra VS. The importance of monophasic Doppler waveforms in the common femoral vein: a retrospective study. J Ultrasound Med. 2007;26:885-91.

41. Osborne T, Sheehan F. An unusual case of deep venous thrombosis in a young patient: congenital absence of the infrarenal portion of the inferior vena cava. Oxf Med Case Reports. 2019;2019:omz053.

42. Kolluri R, Fowler B, Ansel G, Silver M. A novel duplex finding of superficial epigastric vein flow reversal to diagnose iliocaval occlusion. J Vasc Surg Venous Lymphat Disord. 2017;5:358-62.

43. Li Q, Wang Z, Ma X, Tang J, Luo Y. Diagnostic accuracy of contrast-enhanced ultrasound for detecting bland thrombus from inferior vena cava tumor thrombus in patients with renal cell carcinoma. Int Braz J Urol. 2020;46:92-100.

44. Neglén P. Interventions for chronic non-maligant venous obstruction. In: Wittens C, editor. Innovative treatment of venous disorders. Turin: Editione Minerva Medica; 2009. 253-72.

45. Shammas NW, Shammas GA, Jones-Miller S, Radaideh Q, Winter AR, Shammas AN, et al. Predicting iliac vein compression with computed tomography angiography and venography: correlation with intravascular ultrasound. J Invasive Cardiol. 2018;30:452-5.

46. Kandpal H, Sharma R, Gamangatti S, Srivastava DN, Vashisht S. Imaging the inferior vena cava: a road less traveled. Radiographics. 2008;28:669-89.

47. Petik B. Inferior vena cava anomalies and variations: imaging and rare clinical findings. Insights Imaging. 2015;6:631-9.

48. Smillie RP, Shetty M, Boyer AC, Madrazo B, Jafri SZ. Imaging evaluation of the inferior vena cava. Radiographics. 2015;35:578-92.

49. Petik B, Cevik MO, Sirik M, Colak D, Erturk SM. Disappearing Inferior Vena Cava in A Pediatric Patient with Down Syndrome and Hereditary Thrombophilia. J Belg Soc Radiol 2016;100:22.

50. Kaufman LB, Yeh BM, Breiman RS, Joe BN, Qayyum A, Coakley FV. Inferior vena cava filling defects on CT and MRI. AJR Am J Roentgenol. 2005;185:717-26.

51. Zhang L, Yang G, Shen W, Qi J. Spectrum of the inferior vena cava: MDCT findings. Abdom Imaging. 2007;32:495-503.

52. Georgiou NA, Katz DS, Ganson G, Eng K, Hon M. CT of inferior vena cava filters: normal presentations and potential complications. Emerg Radiol. 2015;22:677-88.

53. Li LW, Liu Z, Wang GL, Zhang H, Chen W, Ma J, et al. Comparison of various imaging in the diagnosis of renal cell carcinoma with inferior vena cava tumor thrombus combined with bland thrombus. Beijing Da Xue Xue Bao Yi Xue Ban. 2019;51:678-83.
54. Erhamamci S, Reyhan M, Nursal GN, Torun N, Yapar AF. Incidental diagnosis of tumor thrombosis on FDG PET/CT imaging. Rev Esp Med Nucl Imagen Mol. 2015;34:287-94.

55. Sharma P, Kumar R, Singh H, Jeph S, Patnecha M, Reddy $\mathrm{RM}$, et al. Ultrasonography in patients with Budd-Chiari syndrome: diagnostic signs and prognostic implications. J Hepatol. 2008;49:572-80.

56. Gai YH, Cai SF, Guo WB, Zhang CQ, Liang B, Jia T, Zhang GQ. Sonographic classification of draining pathways of obstructed hepatic veins in Budd-Chiari syndrome. J Clin Ultrasound. 2014;42:134-42.

57. Faraoun SA, Boudjella Mel A, Debzi N, Afredj N, Guerrache Y, Benidir N, et al. Budd-Chiari syndrome: a prospective analysis of hepatic vein obstruction on ultrasonography, multidetector-row computed tomography and MR imaging. Abdom Imaging. 2015;40:1500-9.

58. Gabriele OF, Bell D, Martineau R. Pitfalls in inferior vena cavography. AJR Am J Roentgenol. 1967;100:417-42.

59. Sangster GP, Migliaro M, Heldmann MG, Bhargava P, Hamidian Jahromi A, Thomas-Ogunniyi J. The gamut of primary retroperitoneal masses: multimodality evaluation with pathologic correlation. Abdom Radiol (NY). 2016;41(7): 1411-30. Erratum in: Abdom Radiol (NY). 2016;41:2292.

60. Osman S, Lehnert BE, Elojeimy S, Cruite I, Mannelli L, Bhargava $P$, et al. A comprehensive review of the retroperitoneal anatomy, neoplasms, and pattern of disease spread. Curr Probl Diagn Radiol. 2013;42:191-208.

61. Low RN. Magnetic resonance imaging of the abdomen: applications in the oncology patient. Oncology. 2000;14(6 Suppl 3):5-14.

62. Das CJ, Soneja M, Tayal S, Chahal A, Srivastava S, Kumar A, et al. Role of radiological imaging and interventions in management of Budd-Chiari syndrome. Clin Radiol. 2018;73: 610-24.

63. Karaosmanoglu AD, Uysal A, Onur MR, Hahn PF, Ayhan AS, Ozmen MN, et al. Primary lymphomas of the intraabdominal solid organs and the gastrointestinal tract: spectrum of imaging findings with histopathological confirmation. Abdom Radiol (NY). 2019;44:2988-3005.

64. Hedgire SS, Kudrimoti S, Oliveira IS, Nadkarni N, McDermott S, Hahn PF, et al. Extranodal lymphomas of abdomen and pelvis: imaging findings and differential diagnosis. Abdom Radiol (NY). 2017;42:1096-112.

65. Guerra A, Cunha TM, Félix A. Magnetic resonance evaluation of adnexal masses. Acta Radiol. 2008;49:700-9.

66. Nakashima J, Ueno M, Nakamura K, Tachibana M, Baba S, Deguchi $N$, et al. Differential diagnosis of primary benign and malignant retroperitoneal tumors. Int J Urol. 1997;4: 441-6.

67. McAree BJ, O’Donnell ME, Fitzmaurice GJ, Reid JA, Spence RA, Lee B. Inferior vena cava thrombosis: a review of current practice. Vasc Med. 2013;18:32-43.

68. Epelboym Y, Stecker MS, Fan CM, Killoran TP, Rabkin DJ, Schenker MP. Treatment of malignant inferior vena cava obstruction with Gianturco-Rosch-Z stents: a single center 13-year experience. Clin Imaging. 2020;59:95-9.

69. Kuetting D, Thomas D, Wilhelm K, Pieper CC, Schild HH, Meyer C. Endovascular management of malignant inferior vena cava syndromes. Cardiovasc Intervent Radiol. 2017;40:1873-81.

70. Devcic Z, Techasith T, Banerjee A, Rosenberg JK, Sze DY. Technical and anatomic factors influencing the success of inferior vena caval stent placement for malignant obstruction. J Vasc Interv Radiol. 2016;27:1350-60.

71. Brountzos EN, Binkert CA, Panagiotou IE, Petersen BD, Timmermans H, Lakin PC. Clinical outcome after intrahepatic venous stent placement for malignant inferior vena cava syndrome. Cardiovasc Intervent Radiol. 2004;27:129-36.

72. Fletcher WS, Lakin PC, Pommier RF, Wilmarth T. Results of treatment of inferior vena cava syndrome with expandable metallic stents. Arch Surg. 1998;133:935-8. 
73. Schwein A, Georg Y, Lejay A, Nicolini P, Hartung O, Contassot $D$, et al. Endovascular treatment for venous diseases: where are the venous stents? Methodist Debakey Cardiovasc J. 2018;14:208-13.

74. Chick JFB, Srinivasa RN, Cooper KJ, Jairath N, Hage AN, Spencer B, et al. Endovascular iliocaval reconstruction for chronic iliocaval thrombosis: the data, where we are, and how it is done. Tech Vasc Interv Radiol. 2018;21:92-104.

75. Raju S, Hollis K, Neglen P. Obstructive lesions of the inferior vena cava: clinical features and endovenous treatment. J Vasc Surg. 2006;44:820-7.

76. Grøtta O, Enden T, Sandbæk G, Gjerdalen GF, Slagsvold CE, Bay D, et al. Patency and clinical outcome after stent placement for chronic obstruction of the inferior vena cava. Eur J Vasc Endovasc Surg. 2017;54:620-8.

77. Sebastian T, Dopheide JF, Engelberger RP, Spirk D, Kucher $N$. Outcomes of endovascular reconstruction of the inferior vena cava with self-expanding nitinol stents. J Vasc Surg. Venous Lymphat Disord. 2018;6:312-20.

78. Erben Y, Bjarnason H, Oladottir GL, McBane RD, Gloviczki P. Endovascular recanalization for nonmalignant obstruction of the inferior vena cava. J Vasc Surg Venous Lymphat Disord. 2018;6:173-82.

79. McDevitt JL, Srinivasa RN, Hage AN, Bundy JJ, Gemmete JJ, Srinivasa RN, et al. Total endovenous recanalization and stent reconstruction for naïve non-inferior vena cava filterassociated chronic iliocaval occlusive disease: Placement of 352 venous stents in 69 debilitated patients. Vasc Med. 2019;24:349-58.

80. Barrette LX, McLaughlin SW, Vance AZ, Trerotola SO, Soulen MC, Sudheendra D, et al. Inferior vena cava reconstruction in symptomatic patients using Palmaz stents: a retrospective single-center experience. Ann Vasc Surg. 2020;S0890-5096 (20):30160-6.

81. Neglén P, Hollis KC, Olivier J, Raju S. Stenting of the venous outflow in chronic venous disease: long-term stent-related outcome, clinical, and hemodynamic result. J Vasc Surg. 2007;46:979-90.

82. Delis KT, Bjarnason H, Wennberg PW, Rooke TW, Gloviczki P. Successful iliac vein and inferior vena cava stenting ameliorates venous claudication and improves venous outflow, calf muscle pump function, and clinical status in postthrombotic syndrome. Ann Surg. 2007;245:130-9.

83. Sebastian T, Spirk D, Engelberger RP, Dopheide JF, Baumann FA, Barco S, et al. Incidence of stent thrombosis after endovascular treatment of iliofemoral or caval veins in patients with the postthrombotic syndrome. Thromb Haemost. 2019;119:2064-73.

84. Stuck AK, Reich T, Engelberger RP, Sebastian T, Kucher N. Endovascular treatment of post-thrombotic and nonthrombotic iliofemoral venous outflow obstructions with self-expanding nitinol stents. VASA. 2018;47:319-25.

85. Neglén P, Oglesbee M, Olivier J, Raju S. Stenting of chronically obstructed inferior vena cava filters. J Vasc Surg. 2011;54:153-61.

86. Al-Hakim R, Kee ST, Olinger K, Lee EW, Moriarty JM, McWilliams JP. Inferior vena cava filter retrieval: effectiveness and complications of routine and advanced techniques. J Vasc Interv Radiol. 2014;25:933-9.

87. Dinglasan LA, Trerotola SO, Shlansky-Goldberg RD, Mondschein J, Stavropoulos SW. Removal of fractured inferior vena cava filters: feasibility and outcomes. J Vasc Interv Radiol. 2012;23:181-7.

88. Chick JFB, Jo A, Meadows JM, Abramowitz SD, Khaja MS, Cooper KJ, Williams DM. Endovascular iliocaval stent reconstruction for inferior vena cava filter-associated iliocaval thrombosis: approach, technical success, safety, and two-year outcomes in 120 patients. J Vasc Interv Radiol. 2017;28:933-9.

89. Partovi S, Kalva SP, Walker TG, Taj SM, Ganguli S. Long term follow-up of endo-vascular recanalization of chronic inferior vena cava occlusion secondary to inferior vena cava filters. VASA. 2017;46:121-6.

90. Ye K, Lu X, Li W, Yin M, Liu X, Qin J, et al. Outcomes of stent placement for chronic occlusion of a filter-bearing inferior vena cava in patients with severe post-thrombotic syndrome. Eur J Vasc Endovasc Surg. 2016;52:839-46.

91. Alkhouli M, Zack CJ, Zhao H, Shafi I, Bashir R. Comparative outcomes of catheter-directed thrombolysis plus anticoagulation versus anticoagulation alone in the treatment of inferior vena caval thrombosis. Circ Cardiovasc Interv. 2015;8:e001882.

92. Barge TF, Wilton E, Wigham A. Endovascular treatment of an extensive iliocaval and renal vein thrombosis secondary to inferior vena cava stenosis and May-Thurner type iliac vein compression: a case report. Vasc Endovascular Surg. 2020;54:297-300.

93. Zaghlool DS, Franz RW, Jenkins J. EkoSonic thrombolysis as a therapeutic adjunct in venous occlusive disease. Int J Angiol. 2016;25:203-9.

94. Notten P, Ten Cate-Hoek AJ, Arnoldussen CWKP, Strijkers RHW, de Smet AAEA, Tick LW, et al. Ultrasound-accelerated catheter-directed thrombolysis versus anticoagulation for the prevention of post-thrombotic syndrome (CAVA): a single-blind, multicentre, randomised trial. Lancet Haematol. 2020;7:40-49.

95. Li WD, Li CL, Qian AM, Zhang YQ, Li XQ. Catheter-directed thrombolysis combined with manual aspiration thrombectomy for acute inferior vena cava filter thrombosis. Int Angiol. 2016;35:605-12.

96. Dass P, Robertson J, Muthu C, Holden A. A rare cause of acute pancreatitis: Percutaneous mechanical rheolytic thrombectomy of deep venous thrombosis. Vascular. 2015;23:545-9

97. Rigatelli G, Cardaioli P, Roncon L, Giordan M, Milan T, Zonzin $P$. Combined percutaneous aspiration thrombectomy and rheolytic thrombectomy in massive subacute vena cava thrombosis with IVC filter occlusion. J Endovasc Ther. 2006;13:373-6.

98. Dopheide JF, Sebastian T, Engelberger RP, Haine A, Kucher N. Early clinical outcomes of a novel rheolytic directional thrombectomy technique for patients with iliofemoral deep vein thrombosis. Vasa. 2018;47:56-62.

99. Wang W, Sun R, Chen Y, Liu C. Meta-analysis and systematic review of percutaneous mechanical thrombectomy for lower extremity deep vein thrombosis. J Vasc Surg Venous Lymphat Disord. 2018;6:788-800.

100. Lichtenberg M, Stahlhoff WF, Özkapi A, de Graaf R, Breuckmann F. Safety, procedural success and outcome of the Aspirex(®)S endovascular thrombectomy system in the treatment of iliofemoral deep vein thrombosis - data from the Arnsberg Aspirex registry. VASA. 2019;48:341-6.

101. Wong PC, Chan YC, Law Y, Cheng SWK. Percutaneous mechanical thrombectomy in the treatment of acute iliofemoral deep vein thrombosis: a systematic review. Hong Kong Med J. 2019;25:48-57.

102. Wang ZG, Zhang FJ, Yi MQ, Qiang LX. Evolution of management for Budd-Chiari syndrome: a team's view from 2564 patients. ANZ J Surg. 2005;75:55-63.

103. Ding PX, Han XW, Liu C, Zhang Y, Cheng AL, Wu Y, et al. Longterm outcomes of individualized treatment strategy in treatment of type I Budd-Chiari syndrome in 456 patients. Liver Int. 2019;39:1577-86.

104. Chen ZK, Fan J, Cao C, Li Y. Endovascular treatment for hepatic vein-type Budd-Chiari syndrome: effectiveness and long-term outcome. Radiol Med. 2018;123:799-807.

105. Cheng DL, Xu H, Li CL, Lv WF, Li CT, Mukhiya G, et al. Interventional treatment strategy for primary Budd-Chiari syndrome with both inferior vena cava and hepatic vein involvement: patients from two centers in China. Cardiovasc Intervent Radiol. 2019;42:1311-21. 
106. Meng $X$, Lv Y, Zhang B, He C, Guo W, Luo B, et al. Endovascular management of Budd-Chiari Syndrome with inferior vena cava thrombosis: a 14-year single-center retrospective report of 55 patients. J Vasc Interv Radiol. 2016;27:1592-603.

107. Huang Q, Shen B, Zhang Q, Xu H, Zu M, Gu Y, et al. Comparison of long-term outcomes of endovascular management for membranous and segmental inferior vena cava obstruction in patients with primary Budd-Chiari syndrome. Circ Cardiovasc Interv. 2016;9:e003104.

108. Ding PX, Zhang SJ, Li Z, Fu MT, Hua ZH, Zhang WG. Longterm safety and outcome of percutaneous transhepatic venous balloon angioplasty for Budd-Chiari syndrome. J Gastroenterol Hepatol. 2016;31:222-8.

109. Zhang CQ, Fu LN, Xu L, Zhang GQ, Jia T, Liu JY, Qin CY, Zhu JR. Long-term effect of stent placement in 115 patients with Budd-Chiari syndrome. World J Gastroenterol. 2003;9(11): 2587-91.

110. Zhang W, Wang QZ, Chen XW, Zhong HS, Zhang XT, Chen XD, et al. Budd-Chiari syndrome in China: A 30-year retrospective study on survival from a single center. World J Gastroenterol. 2018;24:1134-43.

111. Ding PX, Han XW, Liu C, Ding JY, Lee EW. Inferior vena cava rupture caused by balloon angioplasty during the treatment of Budd-Chiari syndrome. Cardiovasc Intervent Radiol. 2019;42:1398-1404.

112. Ding PX, Zhang SJ, Li Z, Fu MT, Hua ZH, Zhang WG. Longterm safety and outcome of percutaneous transhepatic venous balloon angioplasty for Budd-Chiari syndrome. J Gastroenterol Hepatol. 2016;31:222-8.

113. Bi Y, Yu Z, Ding P, Ren J, Zhou P, Han X. Long-term outcomes of endoluminal sharp recanalization of occluded inferior vena cava in Budd-Chiari syndrome. J Laparoendosc Adv Surg Tech A. 2019;29:309-15.

114. Cheng DL, Zhu N, Xu H, et al. Outcomes of endovascular interventional therapy for primary Budd-Chiari syndrome caused by hepatic venous obstruction. Exp Ther Med. 2018;16:4141-9.

115. Mukund A, Mittal K, Mondal A, Sarin SK. Anatomic recanalization of hepatic vein and inferior vena cava versus direct intrahepatic portosystemic shunt creation in Budd-Chiari syndrome: overall outcome and midterm transplant-free survival. J Vasc Interv Radiol. 2018;29:790-9.

116. Ding $P X, H e X$, Han XW, Zhang $Y$, Wu Y, Liang XX, Liu C. An individualised strategy and long-term outcomes of endovascular treatment of Budd-Chiari syndrome complicated by inferior vena cava thrombosis. Eur J Vasc Endovasc Surg. 2018;55:545-53.

117. Li T, Zhang WW, Bai W, Zhai S, Pang Z. Warfarin anticoagulation before angioplasty relieves thrombus burden in Budd-Chiari syndrome caused by inferior vena cava anatomic obstruction. J Vasc Surg. 2010;52:1242-5.

118. Fu YF, Xu H, Wu Q, Zhang QQ, Cui YF, Wei N. Combined thrombus aspiration and recanalization in treating BuddChiari syndrome with inferior vena cava thrombosis. Radiol Med. 2015;120:1094-9.

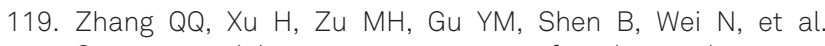
Strategy and long-term outcomes of endovascular treatment for Budd-Chiari syndrome complicated by inferior vena caval thrombosis. Eur J Vasc Endovasc Surg. 2014;47: 550-7.

120. Wang R, Meng Q, Qu L, Wu X, Sun N, Jin X. Treatment of Budd-Chiari syndrome with inferior vena cava thrombosis. Exp Ther Med. 2013;5:1254-8.

121. Ren JZ, Huang GH, Ding PX, Wu G, Han XW, Wang YL. Outcomes of thrombolysis with and without predilation of the inferior vena cava (IVC) in patients with Budd-Chiari syndrome with old IVC thrombosis. Vasc Endovascular Surg. 2013;47:232-8.

\section{History}

Submitted: 07.06.2020

Accepted after revision: 02.11.2020

Published online: 18.01.2021

\section{Conflicts of interests}

No conflicts of interest exist.

\section{Correspondence address}

Dr. med. Peter Franz Klein-Weigel, M.D.

Klinikum Ernst von Bergmann

Klinik für Angiologie

Charlottenstrasse 72

14467 Potsdam

Germany

peter.klein-weigel@klinikumevb.de 